\title{
The machines optimal set development for the construction of automotive roads elements based on the "Norm" for machines employment cost
}

\author{
Zokir Maksudov $^{1 *}$, Mavlyan Kudaybergenov ${ }^{1}$, Sh Kabikenov ${ }^{2}$, and Aydana Sungatollakyzy ${ }^{2}$ \\ ${ }^{1}$ Tashkent State Transport University, Tashkent, Uzbekistan \\ ${ }^{2}$ Karaganda Technical University, Karaganda, Kazakhstan
}

\begin{abstract}
Currently, increasing the efficiency of using the fleet of cars and the functioning of a road enterprise for the construction of highways by forming an optimal set of machines based on the developed normative labor intensity and the production of road construction vehicles for the construction of elements of highways, in a mixed fleet of vehicles of a road enterprise, is a very relevant task. A technique has been developed for optimizing a set of machines for the construction of road elements based on the "norm" of the labor input of the machines. Methodology for standardizing the production of road equipment and calculating the optimal set of vehicles based on the production rate of vehicles for the construction of road elements has been developed. A system of machines has been developed to form a set of machines to construct road elements. Nomograms have been developed for determining and forming the optimal set of machines for the construction of road elements based on the "norm" of the labor input of machines.
\end{abstract}

\section{Introduction}

Currently, increasing the efficiency of the road enterprise through the use of road equipment and the whole park of cars based on the developed cost rate of labor intensity of road construction machines, completed and formed taking into account the technological process of building elements of highways, and also a very urgent task is the relationship of the main weekend parameters of the road equipment.

Especially when the intensity of the traffic flow on the roads has been sharply increasing in recent years, to maintain them at a high technical safety of the movement of cars on highways, road construction enterprises and its machine park must be equipped with various road technicians from the leading company and companies of the developed countries and the CIS countries [1-16].

Recently, modern high-performance, high-power, and comfortable road-building machines have been supplied, and their effective use is achieved during the construction of

\footnotetext{
*Corresponding author: maksudov-55@mail.ru
} 
road elements in a complex-mechanized way, i.e., based on the formed optimal set of machines.

It is known that the elements of building highways include: subgrade, gravel base, and cover; crushed stone base and coating; asphalt concrete pavement and cement concrete pavement. From these bases and pavements, highways are built in several layers (one, two, and three). At each stage of constructing an element of highways, the used road construction machines by types and brands change dramatically, taking into account the main design parameter and the volume of the building highways [2-11]. This circumstance pays special attention to the formation of an optimal set of machines for the construction of highways elements; it is necessary to take into account the multiplicity of the main output (main) parameters of road-building machines that work interconnected in a set.

The construction of the roadbed of highways is carried out by complex mechanized sets of machines and mechanisms. The main options for the comprehensive mechanization of work during the erection of a dredger, according to the name of the leading machine of the optimal set of machines, namely: bulldozer, scraper, excavator-moldboard, excavatortransport, motor grader, etc. [12, 17, 21]. For example, a bulldozer set of machines is used to erect dredges (embankments) from reserves up to 2,0 m, excavations are developed, and the soil is moved in the embankment at a distance of up to $100 \mathrm{~m}$. For this purpose, the most promising bulldozer models are based on caterpillar tractors with a capacity of $96 \div$ $375 \mathrm{~kW}$ and pneumatic wheeled tractors with a capacity of $156 \div 332 \mathrm{kWh}[3-13]$.

A rational set of machines is based on the main driving machine; its main changeable performance is the main one for the rest of the component (auxiliary) machines in the set. A set of machines is a set of coordinated working and interconnected in terms of productivity and other parameters of the main and auxiliary means of mechanization necessary for the performance of all technologically related processes and operations. [15$20]$.

\section{Materials and Methods}

The main driving machine in the set (bulldozer, excavator, asphalt paver, crushed stone distributor, etc.), in terms of its productivity, must ensure the completion of the volume of work in a given time frame at a given pace. The performance of the completing auxiliary machines in the set (bulldozers, rollers, watering machines, dump trucks, etc.) should be five $\div 10 \%$ more than the main driving machine [5-6], [14].

Moreover, the number of leading cars $N_{6}$ necessary to fulfill

a given amount of work within a specified period, determined by the formula

$$
N_{l}=\frac{W}{\Pi_{e l} \cdot n_{c h}} k
$$

where: $W$ is scope of work in physical meters;

$\Pi_{e l}$ is Replaceable operational performance of the leading machine in the appropriate units; $n_{c h}$ is Regulated number of changes in the use of machines $\left(n_{c h}=c \cdot T_{c h}\right)$;

$c$ is number of shifts per day; $T_{c h}$ is regulated period of work performance in working days.

To determine the number of each type of auxiliary machine components, use the formula 


$$
N_{s e}=\frac{\Pi_{e l} \cdot N_{l}}{\Pi_{e . s e}} k
$$

where $\Pi_{\text {e.se }}$ is replaceable operational performance of the completing auxiliary machine of the set; $k$ is coefficient that considers the criteria for optimizing the formation of a set of machines [17-19].

The developed block diagram of the algorithm for the formation and calculation of the optimal set of machines for constructing an element of highways based on the developed standard labor intensity of machines is shown in figure 1.

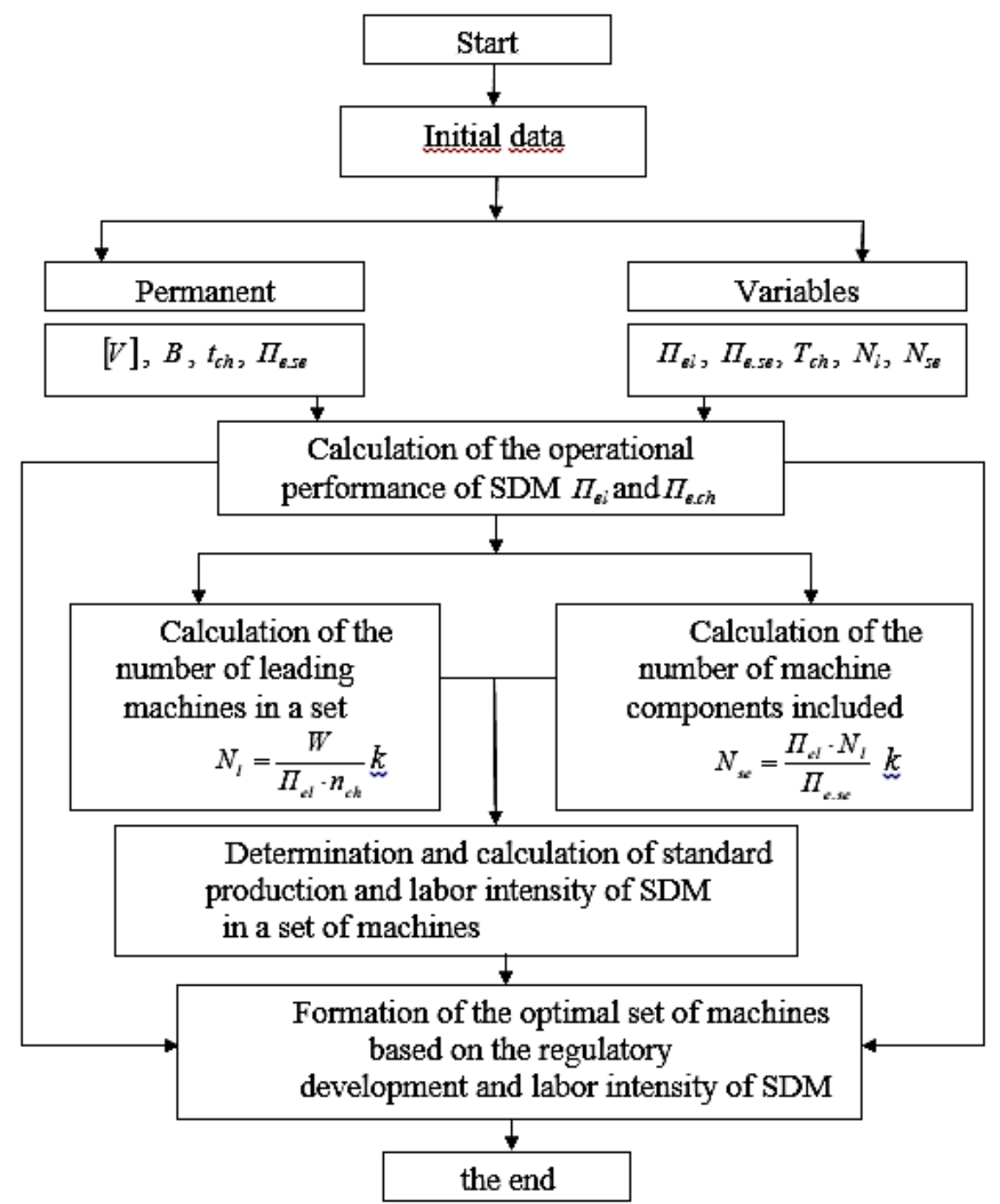

Fig. 1. Block diagram of the algorithm for the formation of a rational set of machines for the construction of an element of highways. 
The nomogram for determining the standard labor intensity of a set of machines for the construction of a roadbed is shown in figure 2 .

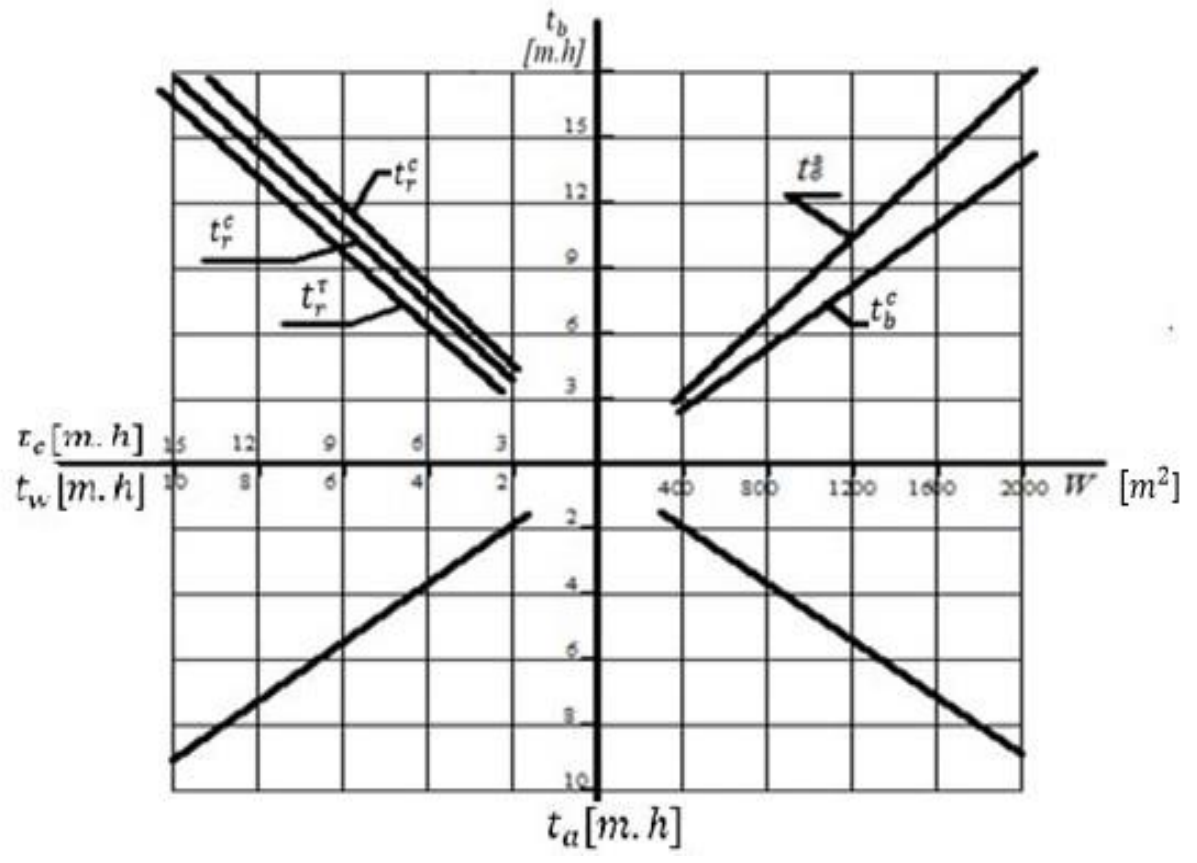

Fig. 2. Nomogram for determining the standard labor intensity of a set of machines for the construction of a roadbed

The construction of foundations from crushed stone and gravel materials provides for the performance of this road work with sets of machines equipped according to the construction technology.

Further, in the work, the work processes of road-building machines included in the rational set of machines for the construction of gravel base were investigated. The standard labor intensity of road equipment for the construction of gravel base was developed.

Based on the results obtained, a nomogram was developed for determining the labor intensity of machines included in a rational set of machines for the construction of a gravel base, which is shown in Fig.3 


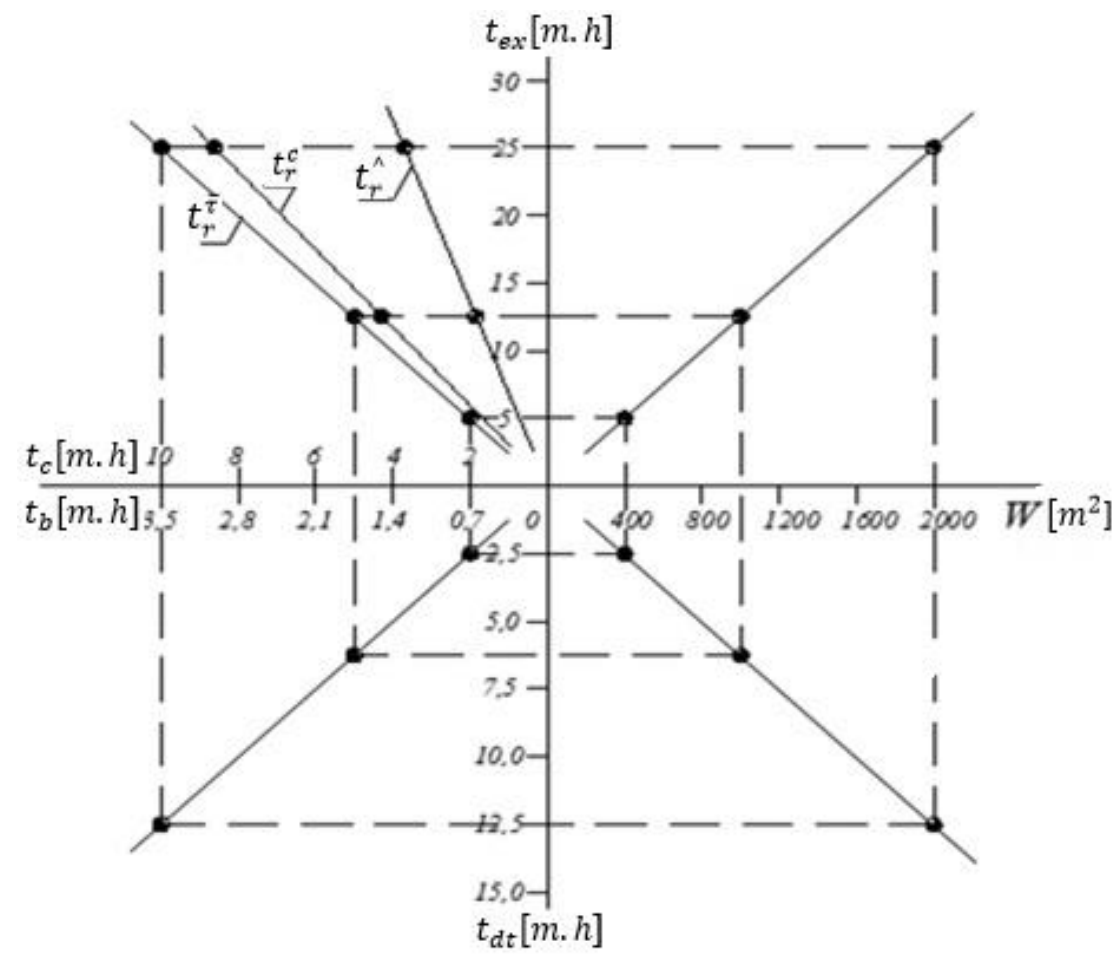

Fig. 3. Nomogram of the formation of a rational set of machines for the construction of gravel base

It is known that the main driving machine in the set, in this case, can be a crushed spreader or a loading-transport machine, based on which the optimal set of machines is formed.

The calculation of the standard labor intensity of the optimal set of machines for the construction of road bases from crushed stone and gravel-sand mixture is carried out according to the developed methodology, taking into account the main parameters of road construction machines $[2,7,9,18]$.

The calculation of the standard labor intensity of the main driving machine of the chipping spreader is made according to the formula:

$$
\Pi_{r}^{e}=\mathrm{V}_{\mathrm{w}}(B-a) \cdot k_{S . r} \cdot k_{h} \cdot k_{t}, \mathrm{~m}^{2} / \mathrm{h}
$$

where $\mathrm{V}_{\mathrm{w}}$ is working speed of machines, $\mathrm{m} / \mathrm{h} ; \mathrm{B}$ is width of the stacked base layer, $\mathrm{m}$; $a$ is width of overlap of adjacent strips in the case of laying a layer in several strips, m; cycle $a=0.1 \div 0.15 \mathrm{~m} ; k_{s . r}$ is the safety factor for compaction is taken depending on the type of material; $k_{s . r}=0.75, k_{t}$ is coefficient of transition from technical productivity to operational productivity.

The developed nomogram for the formation of the optimal set of machines based on the standard labor intensity $t_{i}$ machines for the construction of crushed stone is shown in figure 4 . 


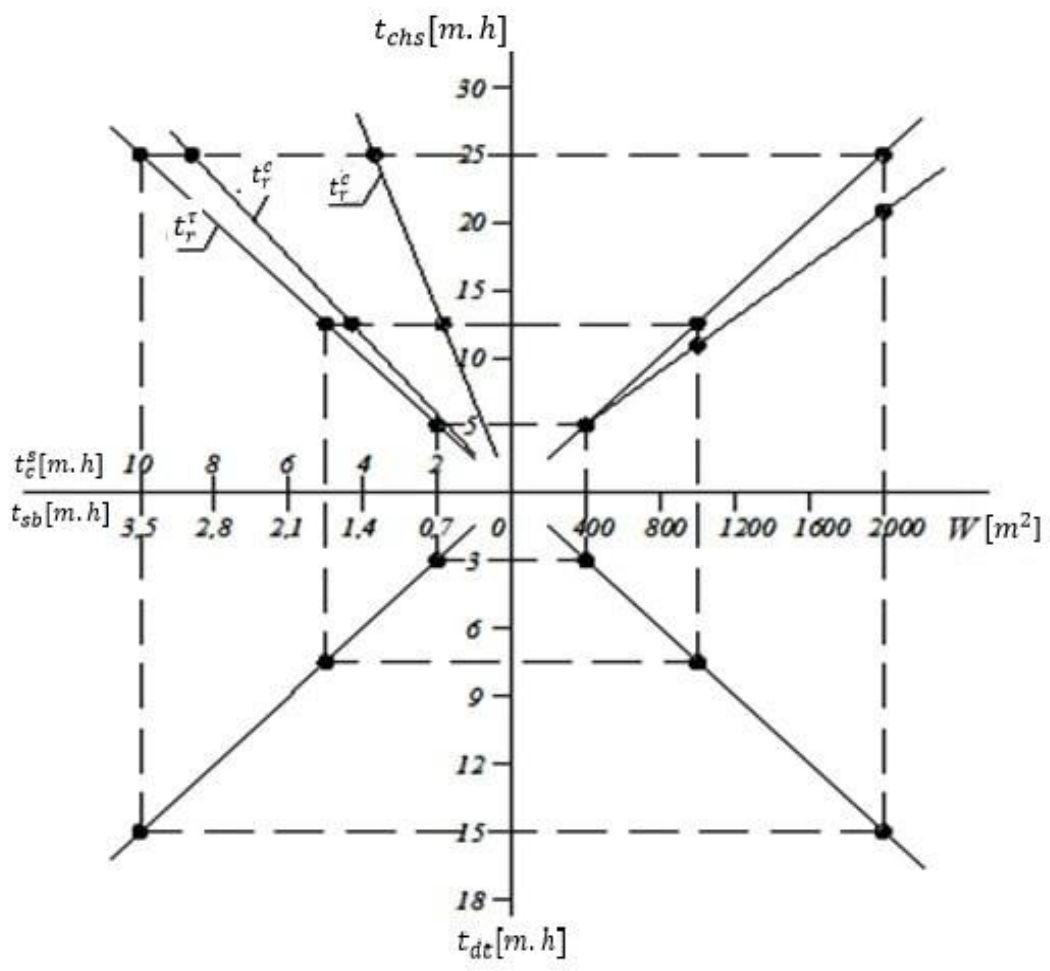

Fig. 4. Nomogram of the formation of the optimal set of machines for the construction of crushed stone base.

\section{Results and Discussion}

It is known that asphalt concrete pavements made of hot and warm mixtures come in one, two, or three layers of varying thickness on a solid, even, and well-drained base. A positive operational quality of asphalt concrete pavements is noiselessness, relatively long service life.

Based on the study results, a nomogram was developed for the formation of an optimal set of machines for the construction of asphalt concrete pavement based on the developed standard production and labor intensity of machines for performing road works, which is shown in figure 5. 


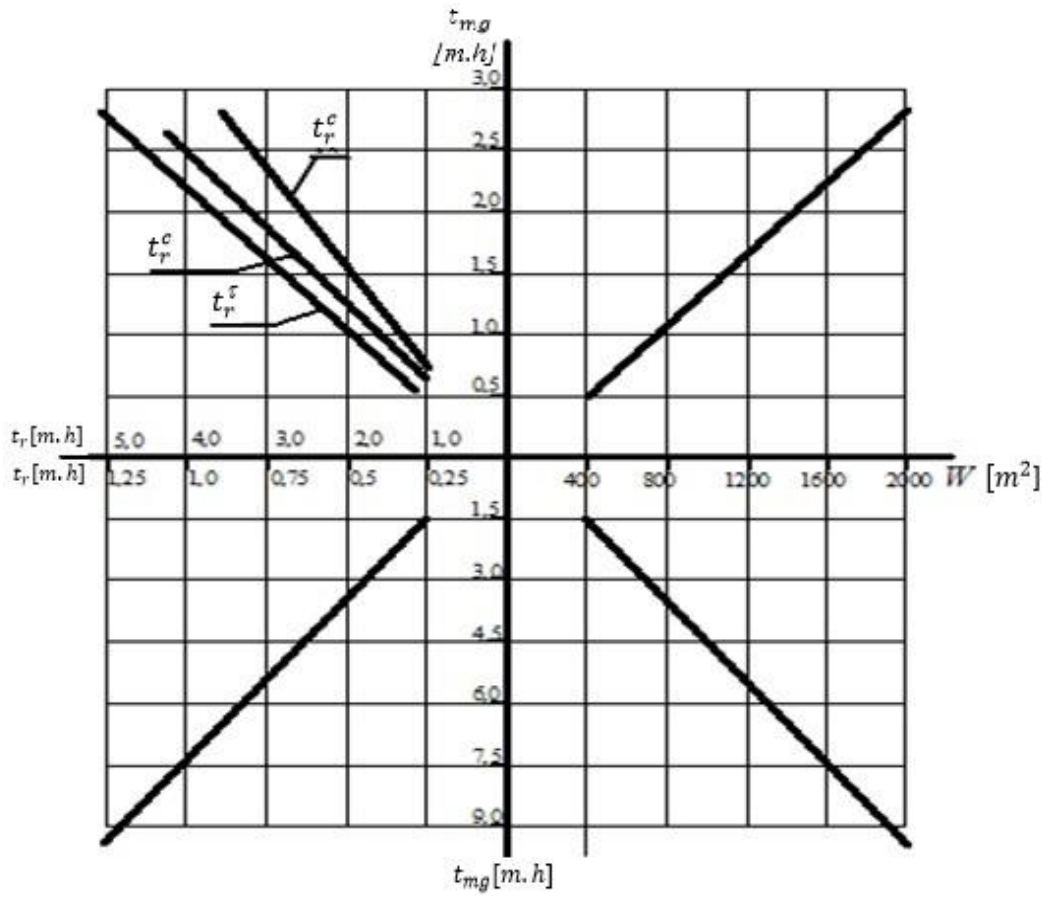

Fig. 5. Optimal set formation nomogrammachines for the construction of asphalt concrete pavement.

The developed standard labor intensity of a set of machines for the construction of an asphalt concrete pavement is presented in table 1 .

Table 1. Standard labor intensity of a set of machines for construction asphalt concrete pavement

\begin{tabular}{|c|c|c|c|c|c|c|c|c|c|c|}
\hline № & Name of & & \multicolumn{8}{|c|}{ Standard meters, $\mathrm{m}^{2}$} \\
\hline 1 & $\begin{array}{c}\text { Asphalt } \\
\text { paver-chick }\end{array}$ & $\begin{array}{c}3.5-8.5 \\
m\end{array}$ & 600 & 800 & 1000 & 1200 & 1400 & 1600 & 1800 & $\begin{array}{c}200 \\
0\end{array}$ \\
\hline 2 & $\begin{array}{l}\text { Light type } \\
\text { rollers }\end{array}$ & $\begin{array}{l}\text { Up to } \\
6.0 \mathrm{t}\end{array}$ & 0.85 & 1.13 & 1.41 & 1.69 & 1.97 & 2.26 & 2.54 & 2.82 \\
\hline 3 & $\begin{array}{l}\text { Medium } \\
\text { rollers }\end{array}$ & $8-12 \mathrm{t}$ & 1.02 & 1.35 & 1.69 & 2.03 & 2.37 & 2.70 & 3.04 & 3.38 \\
\hline 4 & $\begin{array}{c}\text { Heavy } \\
\text { pneumatic } \\
\text { rollers }\end{array}$ & $\begin{array}{l}\text { More } \\
\text { than } \\
14.0 \mathrm{t}\end{array}$ & 1.39 & 1.85 & 2.31 & 2.77 & 3.23 & 3.70 & 4.16 & 4.62 \\
\hline 5 & $\begin{array}{c}\text { Asphalt } \\
\text { distributor }\end{array}$ & 70001 & 1.53 & 2.04 & 2.55 & 3.06 & 3.57 & 4.08 & 4.59 & 5.10 \\
\hline 6 & Dump truck & $\begin{array}{l}\text { More } \\
\text { than } \\
20.0 \mathrm{t}\end{array}$ & 0.37 & 0.50 & 0.62 & 0.74 & 0.87 & 0.99 & 1.12 & 1.24 \\
\hline
\end{tabular}

The obtained results of this study (table 1) allow you to form an optimal set of machines, taking into account the standard labor intensity of machines for a specific volume of work in the construction of roadbed, crushed stone base, and asphalt concrete pavement. 


\subsection{Practical application}

The developed methodology for optimizing a set of vehicles for the construction of road elements based on the "norm" of the labor intensity of machines has wide practical application in a road enterprise, which allows increasing the efficiency of using the fleet of cars. The developed methodology for standardizing the production of road equipment and calculating the optimal set of machines based on the production rate of machines for the construction of road elements and the nomogram for determining and forming the optimal set of machines for the construction of road elements based on the "norm" of the labor intensity of machines have great practical applications when compiling a set of machines; they do not create difficulties in determining and calculating operational parameters, as well as in forming an optimal set of machines.

\section{Conclusions}

The developed nomograms allow, at different values of the volume of work $[\mathrm{W}]$, to determine the labor intensity of machines included in the optimal set of machines, with this allows you to form an optimal set of machines for the construction of subgrade, gravel, and crushed stone base and pavement, as well as asphalt concrete pavement and in general in the construction of elements of highways of different categories.

\section{References}

1. Permyakov V.B., Salikhov, R.F., Musagitova G.N., YU Levin, N. Designing optimal structure of road construction machines kits, Journal of Physics, Conference Series, 1260 (8), № 082004, (2019), doi: 10.1088/1742-6596/1260/8/082004

2. Permyakov V.B., Ivanov V.N. The effectiveness of the use of mechanization facilities in the construction industry, Omsk: SibADI, (2002)

3. Ivanov V.N., Salikhov R.F., Grusnev M.G. Optimal planning of the functioning of systems of production, technical operation and development of road-building machinery parks, Omsk: SibADI, (2013)

4. Sabha F.N. Modeling reclamation earthwork operations using special purpose simulationtool, February (2012)

5. Abou rizk S.M., Mohamed Y. Optimal construction project planning, Proc. Winter Simulation Conf. IEEE, 2 pp. 1704-1708, Piscataway, New Jersey, (2002)

6. Abourizk S.M, HALPIN D., Mohamed Y., Hermann U. Research in modeling and simulation for improving construction engineering operations, Journal of Construction Engineering and Management 137 (10) pp. 843-852 October (2011)

7. Obergrieber M. Digital tools to integrated infrastructure, building, planning, The example of Rails-and road construction doctoral thesis, Tehnical universuty of Munich, (2016)

8. Salikhov R.F. Improved methods of forecasting changes in the operational performance of construction machines from operating time, mechanization of construction 78 (4) pp. 46-50, (2017)

9. Salikhov R.F., Popkov V.I. Methodology for calculating of change of productivity of a single-bucket excavator in the course of operating time, mechanization of construction, 79 (3) pp. 26-31, (2018)

10. Ivanov V.N., Trofimova L.S., Linev F.V. A model of formation and development of technological complexes of machines for highway construction, construction and road building machinery, 6, pp. 22-25, (2013) 
11. Khankelov T., Askarhodzhaev T., Mukhamedova N. Determination of key parametres of devise for sorting municipal solid waste, Journal of Critical Reviews, 7(4), pp.2728, (2020)

12. Khankelov T., Tursunov SH., Maksudov Z. Domestic Solid Waste Crusher, International Journal of Psychological Rehabilitation, 24,(07), pp. 8090-8091, (2020)

13. Khankelov T.K. A theory of sorting solid domestic waste, Stroitelnye Dorozhnye Mashiny, 5, pp. 34-36, (2001)

14. Tursunov, SH.S. Analysis of existing desings of crushers for crushing municipal solid waste, International Journal for Innovative Engineering and Management Research, 10(01), pp. 274-276 (2021)

15. E. Ray Brown., Hot-Mix Asphalt Paving, American Association of State Highway and Transportation Officials, pp. 180-183, (2000)

16. ASKARHODZHAEV T., MAKSUDOV Z. Industry norms of labor and mechanized costs of modern mechanisms and equipment in the construction, repair and maintenance of highways. Departmental building codes. VSN 62-11. Tashkent, 2012, p. 180.

17. Askarhodzhaev T., Maksudov Z. Requirements of road equipment for routine repair and maintenance of highways, Departmental rules and regulations, MKN 36-2008, p. 96. Tashkent, (2013)

18. Askarkhodzhaev T.I., Pirnaev SH.A., Mirnigmatov B.T., Abdukarimova SH.M. Research of The Processes of Wearing the Working Bodies of Road Mills, International Journal of Psychological Rehabilitation, 24(07), p. 8052-8062, (2020)

19. Maksudov Z.T., Khankelov T.K., Yusupova N.Z. Formation of a rational set of cars based on the developed standard labor intensity for the construction and repair of highways, Belarusian State University of Transport. pp. 157-161, Gomel, (2019)

20. Askarhodzhaev T.I., Maksudov Z.T. Operation of road-building machines, A textbook for university students, p. 324, Tashkent, (2011)

21. Maksudov Z.T., Kudaybergenov M, Ismailov J. On the frequency of service maintenance of the "SHANTUI SD 32" bulldozer in terms of fuel consumption and machine production, Collection of scientific papers of the eighth international scientific-practical conference, pp.151-154, Almaty, (2019) 